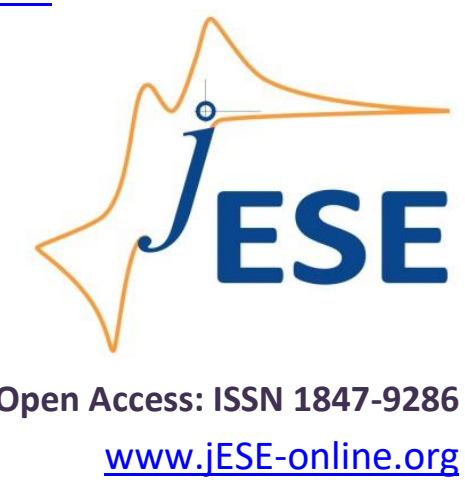

Original scientific paper

\title{
Pencil graphite electrodes as bioanodes for enzymatic glucose biofuel cell
}

\author{
Madhavi Bandapati ${ }^{1}$, Sanket Goel ${ }^{2}$ and Balaji Krishnamurthy ${ }^{1, \bigotimes}$ \\ ${ }^{1}$ Department of Chemical Engineering, Birla Institute of Technology and Science (BITS) Pilani, \\ Hyderabad Campus, Hyderabad, India \\ ${ }^{2}$ MEMS and Microfluidics Lab, Department of Electrical and Electronics Engineering, Birla Institute \\ of Technology and Science (BITS) Pilani, Hyderabad Campus, Hyderabad, India
}

Corresponding author: ${ }^{凶}$ balaji@hyderabad.bits-pilani.ac.in, balaji.krishb1@gmail.com

Received: March 9, 2020; Revised: May 19, 2020; Accepted: May 26, 2020

\begin{abstract}
This study investigates the performance of pencil graphite $(P G)$ electrodes to identify the grade of pencil most suitable as bioanode for enzymatic glucose biofuel cell. Pencils of $H$, $3 \mathrm{H}, \mathbf{5 H}$ and $\mathrm{B}$ grades are selected for this study. The surfaces of different grade PGs are modified with carboxylic acid functionalized multi walled carbon nanotubes (COOH-MWCNT/PG), followed by immobilization with glucose oxidase (GOx) to fabricate the respecttive bioanodes (GOx/COOH-MWCNT/PG). Morphological and electrochemical characterizations are carried out using scanning electron microscopy, electrochemical impedance spectroscopy, cyclic voltammetry and energy dispersive $X$-ray spectroscopy. All tested PG electrodes exhibited positive results with variable response characteristics towards glucose oxidation reaction. B-grade PG bioanode is found to have the highest coverage of the deposited nanobiocomposite with the fastest electron transfer rate. The half-cell electrode assembly with this grade of PG recorded the highest current density of $4.25 \mathrm{~mA} \mathrm{~cm}^{-2}$ at physiological glucose conditions (5 $\mathrm{mM}$ glucose, $\mathrm{pH}$ 7.0). Enzymatic glucose biofuel cell assembled with B-grade $P G$ bioanode and platinum cathode generated an open circuit potential of $149 \mathrm{mV}$ and maximum power density of $0.789 \mu \mathrm{W} \mathrm{cm}$ from $5 \mathrm{mM}$ glucose at ambient conditions $\left(25 \pm 3^{\circ} \mathrm{C}\right)$. The results obtained for $B$-grade $P G$ bioanode are comparable to those of conventional carbon and glassy carbon electrodes, thus demonstrating its applicability to enzymatic glucose biofuel cells.
\end{abstract}

\section{Keywords}

Pencil graphite electrode; bioanode; glucose oxidase; multiwalled carbon nanotubes; enzymatic glucose biofuel cell. 


\section{Introduction}

Enzymatic glucose biofuel cells (EGBFCs) employ enzymes as catalysts which exhibit extremely specific electro-catalytic activities for biochemical and biological reactions [1]. These enzymes have relatively short life-span and redox centers are often buried deep inside the protein/glycoprotein shell, requiring thus pragmatic selection of electrode materials and fabrication of electrodes [2]. To establish efficient electron transfer between enzyme active sites and electrode, the enzyme must be supported with appropriate solid support, i.e. conducting support matrix, with adequate materials for binding and encapsulation, and with transport mediators [3]. To maximize the current output of the enzymatic redox reactions, a variety of materials are being explored as electrode substrates, including functionalized/conductive electroactive polymers, biocompatible composites, composites of organometallic compounds and transition metal-based complexes, hydro-gel and sol-gel materials, nanomaterials such as nano-metal oxides and composites [4,5].

Among low cost electrode substrates, pencil graphite (PG) electrodes have already established an active area of research. Aoki et al. have reported that the nature of PG influences the voltammetric and electroanalytical response of the analyte [6]. David et al. showed that just like other carbon-based working electrodes, PG presents high chemical and mechanical stability and large working potential window (-0.8 V to $0.6 \mathrm{~V}$ vs. SCE in acidic and alkaline solutions) [7]. Karuiki et al. have shown that the electron transfer rate of $\mathrm{HB}$ grade $\mathrm{PG}$ is similar to glassy carbon electrode [8]. Tavare et al. have found out that most PGs have electrical resistance less than $5 \Omega$ and hence could be considered as electrode materials [9].

Typically, PG comprises clay and graphite. Increasing graphite content increases softness of pencil, while increasing the clay content adds hardness [10]. Accordingly, different grades of PG ranging from $8 \mathrm{~B}$ (softest) to $9 \mathrm{H}$ (hardest), have already been studied for various electroanalytical applications [11,12]. Among different grade PGs (HB, H, F, 2H, 4H and 6H), Wang et al. have shown that $\mathrm{HB}$ grade pencil generated the most favorable response for stripping voltammetric analysis of RNA. The authors have also shown that $6 \mathrm{H}$ pencil displays the most favorable signal to background ratio in the electrochemical detection of deoxyribonucleic acid (DNA) $[13,14]$. Alipour et al. and Ozcan et al. have shown that electrochemically modified PG can be used for detection and determination of morphine and uric acid concentration in blood streams $[15,16]$. Kara et al. have used PG for electrochemical investigation of DNA sequences present in herpes viruses [17]. Several papers have reported the results of comparison between performance of PG and other electrodes with respect to electroanalysis of different compounds [18]. Rubianes et al. have compared the performance of several graphite-based electrodes including PG for amperometric determination of dopamine [19]. Several authors have also postulated low background current as one of the most important features of PG [20-22]. Thus, use of PG electrodes for several electroanalytical applications including biosensors, is well known and well established in the literature. Table 1 shows the summary of basic electroanalytical data for few surface modified PG electrodes.

Contrary to biosensors, however, EGBFCs need to produce high potential and current. To enhance the overall performance of EGBFC, enzyme activity and loading need to be improved through several electrode surface modification techniques. Also, the output can be multiplied by cell stacking [3].

Application of PG in EGBFC requires exclusive studies, encouraging thus novel research in this area. In the pioneering work concerning the application of PG in EGBFC, our recent research has already established $5 \mathrm{H}$-grade $\mathrm{PG}$ as the optimal biocathode. 
Table 1. Electroanalytical data of pencil graphite (PG) electrode for various analytes

\begin{tabular}{ccccc}
\hline PG based electrode & Analyte & \multicolumn{2}{c}{ Linear range } & Detection limit Ref. \\
\hline Carmoisine-Cu(II) complex/polyaniline/PG & $\mathrm{Cu}$ (II) & $5 \times 10^{-6}-1 \times 10^{-1} \mathrm{M}$ & $2 \times 10^{-6} \mathrm{M}$ & {$[23]$} \\
\hline Poly(4-vinyl pyridine)/PG & $\mathrm{Cd}$ (II) & $1 \times 10^{-7}-1 \times 10^{-1} \mathrm{M}$ & $2.51 \times 10^{-8} \mathrm{M}$ & {$[24]$} \\
\hline Diphenylcarbazide/polyaniline/PG & $\mathrm{Cr}$ (IV) & $1 \times 10^{-6}-1 \times 10^{-1} \mathrm{M}$ & $8 \times 10^{-7} \mathrm{M}$ & {$[25]$} \\
\hline Platinum nanoparticle/PG & $\mathrm{H}_{2} \mathrm{O}_{2}$ & $10-110 \mu \mathrm{M}$ & $3.6 \mu \mathrm{M}$ & {$[26]$} \\
\hline Gold nanoparticles/PG & $\mathrm{N}_{2} \mathrm{H}_{4}$ & $0.05-1000 \mathrm{~mol} \mathrm{~L} \mathbf{- 1}^{-1}$ & $42 \mathrm{nmol} \mathrm{L}^{-1}$ & {$[27]$} \\
\hline Gold nanoparticles/PG & Uric acid & $0.1-0.6 \mathrm{mM}$ & - & {$[28]$} \\
\hline Gold nanoparticle/carbon paste/PG & Glucose & $0.0-33.4 \mathrm{mM}$ & $14.2 \mu \mathrm{M}$ & {$[29]$} \\
\hline Single walled carbon nanotubes /PG & p53 Gene & $3.2-8.0 \mu \mathrm{M}$ & $0.88 \mu \mathrm{M}$ & {$[30]$} \\
\hline Multiwalled carbon nanotubes/PG & Buprenorphine & $1.0-109.0 \mathrm{pM}$ & $0.6 \mathrm{pM}$ & {$[31]$} \\
\hline Gold nanoparticles/chitosan/PG & Deferiprone & $0.005-1000 \mu \mathrm{M}$ & $5 \mathrm{nM}$ & {$[32]$} \\
\hline Copper hexacyanoferrate nanostructures (CuHCF/PG) & L-cysteine & $1-13 \mu \mathrm{M}$ & $0.13 \mu \mathrm{M}$ & {$[33]$} \\
\hline SWCNTs-chitosan/PG & Vitamin B12 & $5.0-100.0 \mathrm{nM}$ & $0.89 \mathrm{nM}$ & {$[34]$} \\
\hline SWCNTs-chitosan/PG & DNA & $10-80 \mu \mathrm{mL}$ & $13.2 \mu \mathrm{mL} \mathrm{mL}^{-1}$ & {$[35]$} \\
\hline MWCNT/PG & Methadone & $0.1-15 \mu \mathrm{M}$ & $0.087 \mu \mathrm{M}$ & {$[36]$} \\
\hline
\end{tabular}

In addition, it was shown that PG electrodes of $5 \mathrm{H}$ and $\mathrm{B}$ grades set as biocathode and bioanode yield the highest full cell performance $[37,38]$. In continuation of this effort, it would be important to find which PG grade is best suited for bioanode. Accordingly, the objective of the present research work is to evaluate the performance of various grades $(\mathrm{H}, 3 \mathrm{H}, 5 \mathrm{H}$ and $\mathrm{B})$ of $P G$ in order to identify the grade best suited for bioanode in EGBFC. The surface of these grades of PG were modified first by dip coating of carboxylic acid functionalized multiwalled carbon nanotubes ( $\mathrm{COOH}-\mathrm{MWCNT/PG}$ ) and then by covalent immobilization of glucose oxidase (GOx) enzyme, forming GOx/COOH-MWCNT/PG electrode. The relative performances of fabricated PG bioanodes are studied for their efficiency towards oxidation of glucose.

For this study, a mediated electron transfer (MET) is employed using $p$-benzoquinone as a redox mediator to improve the rate of electron transfer between enzyme and electrode. In anodic enzyme glucose oxidase, the redox active centers are deeply buried in the protein structure making direct electron transfer very difficult [39]. Half-cell and full cell performances of the optimized pencil grade bioanode are evaluated to validate its application to EGBFC.

\section{Experimental}

\section{Chemicals}

Analytical grade chemicals and materials were procured from Sigma-Aldrich and used as received. They include dibasic sodium phosphate $\left(\mathrm{Na}_{2} \mathrm{HPO}_{4}\right)$, monobasic sodium phosphate $\left(\mathrm{NaH}_{2} \mathrm{PO}_{4}\right)$, sodium hydroxide $(\mathrm{NaOH})$, hydrogen chloride $(\mathrm{HCl})$, 1-Ethyl-3-(3-dimethylaminopropyl) carbodiimide $(E D C)$, acetone, potassium ferricyanide $\left(\mathrm{K}_{3}\left[\mathrm{Fe}(\mathrm{CN})_{6}\right]\right)$, dimethyl sulfoxide (DMSO), $\mathrm{D}$-(+)-glucose, N-hydroxy succamide (NHS), p-benzoquinone (PBQ), carboxylic acid functionalized multiwalled carbon nanotubes, (COOH-MWCNT) with average diameter and length $9.5 \mathrm{~nm}$ and $1.5 \mu \mathrm{m}$. Glucose oxidase (GOx) from Aspergillus niger was used as biocatalyst for glucose oxidation reaction. It was stored in lyophilized powder at $-20^{\circ} \mathrm{C}$. Enzyme solution was freshly prepared before each experiment. Pencil graphite of $\mathrm{H}, 3 \mathrm{H}, 5 \mathrm{H}$ and $\mathrm{B}$ of Apsara brand, India, with $1 \mathrm{~cm}$ length and $2 \mathrm{~mm}$ diameter, were purchased locally.

\section{Equipment}

Electrochemical measurements were performed using Autolab Potentiostat/Galvanostat PGSTAT $302 \mathrm{~N}$ model (Metrohm, Netherlands) with NOVA 1.11 version software, Biologic model SP-150. The 
morphological and elemental composition studies of fabricated PG based bioanodes were performed using scanning electron microscopy performed by Apreo SEM with an energy dispersive X-ray (EDX) instrument.

\section{Procedures}

All experiments were carried out at room temperature $\left(25 \pm 3{ }^{\circ} \mathrm{C}\right)$ and all solutions were made from milli-Q grade deionized water having specific resistivity $18.2 \mathrm{M} \Omega \mathrm{cm}$.

\section{Electrolyte and electrode material}

A solution of $0.1 \mathrm{M}$ phosphate buffer was employed as electrolyte for carrying out electrochemical measurements. Appropriate proportions of $0.2 \mathrm{M} \mathrm{Na}_{2} \mathrm{HPO}_{4}$ and $0.2 \mathrm{M} \mathrm{NaH}_{2} \mathrm{PO}_{4}$ were added and the $\mathrm{pH}$ was fine tuned to 7.0 by either acid $(1.0 \mathrm{M} \mathrm{HCl})$ or base $(1.0 \mathrm{M} \mathrm{NaOH})$ solutions.

The pencil leads were extracted by peeling the wooden shell using a razor blade. All peeled pencil leads were washed with $\mathrm{HCl}(0.5 \mathrm{M})$ for $2 \mathrm{~min}$ in ultrasonication bath followed with acetone wash for $2 \mathrm{~min}$ using sonicator. The cleaned pencil leads were dried at $90{ }^{\circ} \mathrm{C}$ for $2 \mathrm{~h}$ in hot air oven to remove moisture content. The pencil leads prepared in this manner were then subjected to surface modification to obtain the pencil graphite electrodes.

\section{Surface modification of $P G$}

Dip coating technique was employed to coat COOH-MWCNT on the surface of cleaned PG. $1.0 \mathrm{mg} \mathrm{ml}^{-1}$ dry $\mathrm{COOH}-\mathrm{MWCNT}$ was added to DMSO and dispersed using a sonicator. The cleaned pencils were dipped in this MWCNT dispersion to ensure proper wetting of PG surface and this was followed by drying to evaporate solvent. For effective adsorption of MWCNT on the surface of PG, the process of wetting followed by drying was repeated four times.

\section{Enzyme immobilization on electrode}

Initially, the activation of carboxylic groups was carried out by immersing COOH-MWCNT/PG in EDC/NHS (1:1) solution for $2 \mathrm{~h}$. Thereafter, GOx, the most commonly used enzyme for oxidation of glucose [40], was covalently immobilized on COOH-MWCNT/PG. $7.0 \mathrm{mg}$ of GOx enzyme mixed in $1.0 \mathrm{ml}$ of PBS (0.1 M, pH 7.0) was cast on the surface of COOH-MWCNT/PG and then allowed to dry for $4 \mathrm{~h}$ at ambient temperature in proper ventilation. Here, GOx enzyme becomes covalently associated to activated $\mathrm{COOH}$ groups in MWCNT by amide bond through bioconjugation technique. Later, the prepared GOx/COOH-MWCNT/PG was rinsed in PBS to remove unattached enzymes.

\section{Electrochemical characterization}

Cyclic voltammetry (CV) measurements were performed in three-electrode cell assembly comprising respective grade of $\mathrm{GOx} / \mathrm{COOH}-\mathrm{MWCNT} / \mathrm{PG}$ as the working electrode, platinum wire as the counter electrode and $\mathrm{Ag} / \mathrm{AgCl}$ (sat. $\mathrm{KCl}$ ) (Metrohm) as the reference electrode. The potential was swept between $-0.6 \mathrm{~V}$ to $0.6 \mathrm{~V}(\mathrm{vs}$. $\mathrm{Ag} / \mathrm{AgCl})$ with scan rates varied from 10 to $50 \mathrm{mV} \mathrm{s}^{-1}$. It was observed that $10 \mathrm{mV} \mathrm{s}^{-1}$ was the optimum scan rate for all tested grades of $\mathrm{PG}$, and therefore, this scan rate was maintained for all experiments. All measurements were made with regard to the geometrical surface area $\left(0.66 \mathrm{~cm}^{2}\right)$ of prepared bioanodes.

To measure effective electrode surface area (ESA), CV was repeated for the same electrode system in $4 \mathrm{mM} \mathrm{K}_{3}\left[\mathrm{Fe}(\mathrm{CN})_{6}\right]$ dissolved in $0.1 \mathrm{M} \mathrm{KNO}_{3}$ in a voltage range $-0.2-0.8 \mathrm{~V}$ for a series of scan rates ranging from 20 to $100 \mathrm{mV} \mathrm{s}^{-1}$ [41].

Electrochemical impedance spectroscopy was performed over the frequency range of $10 \mathrm{kHz}$ to 10 $\mathrm{mHz}$, at an amplitude of $5 \mathrm{mV}$, resulting in Nyquist plots (-Z" vs. $\left.Z^{\prime}\right)$ of GOx/COOH--MWCNT/PG [42]. 
All experiments were repeated with three sets of electrodes fabricated for each grade of pencil graphite to ensure the effectiveness of the fabrication procedure and to evaluate the consistency and reproducibility of the results obtained.

\section{Half-cell and full cell assembly with modified PG bioanode}

Half-cell measurements were carried out using a conventional three-electrode system of $25 \mathrm{ml}$ volume capacity comprising the prepared GOx/COOH-MWCNT/PG (modification described above) as the working electrode, platinum wire as the counter electrode and $\mathrm{Ag} / \mathrm{AgCl}(\mathrm{sat} . \mathrm{KCl})$ as the reference electrode. The solution of $0.1 \mathrm{M}, \mathrm{pH}$ 7.0 PBS containing $5 \mathrm{mM}$ glucose as redox species was used as the electrolyte. To promote MET, $2 \mathrm{mM}$-benzoquinone (PBQ) was added to the electrolyte as a redox mediator [43]. The electrolyte was purged with $\mathrm{N}_{2}$ gas for 15 min before each experiment to avoid the interference of oxygen to glucose oxidation reaction at anode. Experiments carried out on the said grades of pencils at various scan rates showed that maximum performance was obtained at scan rate of $10 \mathrm{mV} \mathrm{s}^{-1}$. Accordingly, this scan rate was considered as the optimized parameter for carrying out rest of the experiments.

An assembly of enzymatic glucose biofuel cell was used to test GOx/COOH-MWCNT composite modified PG based bioanode using Biologic-150 Potentiostat (Biologic Science instruments, France). EGBFC comprises of $10 \mathrm{ml}$ single compartment membrane-less chamber with GOx/COOH-MWCNT composite modified PG as bioanode and platinum wire as biocathode. The cell is fed with $0.1 \mathrm{M}$, $\mathrm{pH}$ 7.0 PBS containing $5 \mathrm{mM}$ glucose as anodic fuel and ambient air for cathode. PBQ and ABTS were used as anode and cathode redox mediators, respectively.

Any half-cell and full cell set up was configured separately for each tested grade of PG bioanode and the measurements were recorded individually.

Polarization studies were conducted to evaluate the voltage and power output generated by EGBFC. The maximum power output of assembled PG based EGBFC at each known resistance was calculated by multiplying stabilized current and potential. The full cell performance parameters such as current and power densities were calculated based on the geometrical surface area of the electrode. The real images of the experimental set up are shown in Figure 1.

\section{Measurements}

Effective surface area of electrode

Effective surface area (ESA) of COOH-MWCNT/PG electrode was evaluated using Randles-Ševčik equation describing the effect of scan rate on peak current in cyclic voltammetry experiments [44]:

$$
i_{\mathrm{p}}=2.69 \times 10^{5} n^{3 / 2} D^{1 / 2} C A v^{1 / 2}
$$

In eq. (1), $i_{\mathrm{p}}$ is peak current, $n$ represents the number of electrons transferred during redox reaction, $D\left(\mathrm{~cm}^{2} \mathrm{~s}^{-1}\right)$ represents diffusion coefficient of reaction species, $v$ is the sweep or scan rate $\left(\mathrm{V} \mathrm{s}^{-1}\right), C$ is concentration $(\mathrm{M})$ of reaction species, and $A$ symbolizes the effective surface area of electrode $\left(\mathrm{cm}^{2}\right)$. In present experiments, $4 \mathrm{mM} \mathrm{K}_{3}\left[\mathrm{Fe}(\mathrm{CN})_{6}\right]$ was applied generating $\mathrm{Fe}(\mathrm{CN})_{6}{ }^{-3} / \mathrm{Fe}(\mathrm{CN})_{6}{ }^{-4}$ redox reaction and $D$ was stated as $6.70 \times 10^{-6} \mathrm{~cm}^{2} \mathrm{~s}^{-1}$.

Peak currents $\left(i_{\mathrm{p}}\right)$ were measured at scan rates varying from $20-100 \mathrm{mV} \mathrm{s}^{-1}$ using $\mathrm{CV}$ and the slope $(k)$ of the obtained linear expression for $i_{p} v s . v^{1 / 2}$ was obtained. The slope is then substituted into the following equation to express ESA $(A)[41]$ :

$$
A=k /\left(2.69 \times 10^{5} n^{3 / 2} D^{1 / 2}\right)
$$




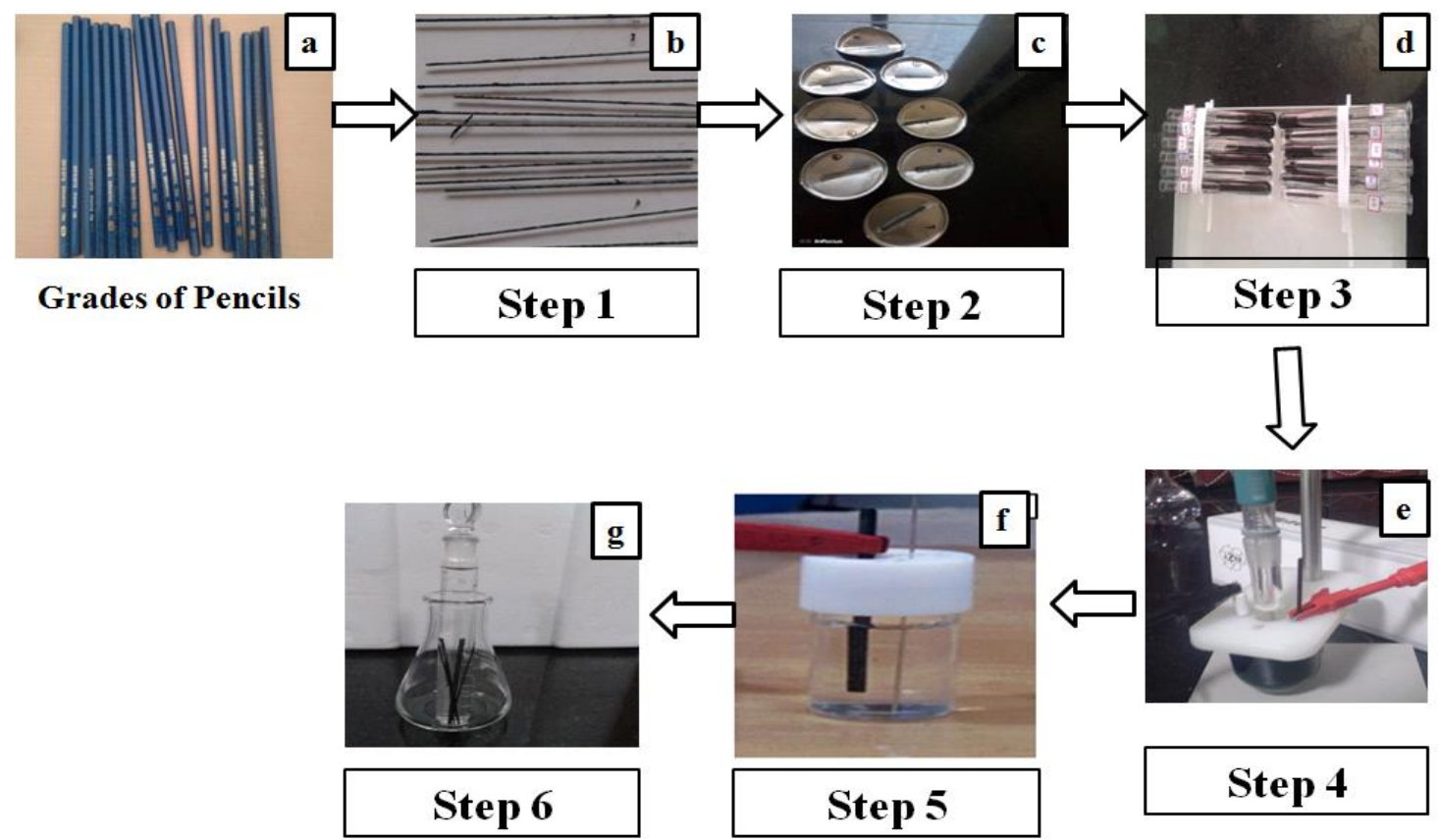

Figure 1. Real images of stepwise process of PG electrode fabrication: (a) pencil graphite of different grades;

(b) peeled and pretreated PG; (c) MWCNT modified PG; (d) enzyme immobilization; (e) PG based bioanode half-cell performance; (f) PG based bioanode full cell EGBFC; $(g)$ storage of fabricated PG bioanode

\section{Electron transfer kinetics}

\section{Electron transfer reaction rate (ETR) constant}

The Laviron equation [45] was employed to measure ETR constant $(\gamma)$ of each grade of fabricated PG based bioanode:

$$
\log \gamma=\alpha \log (\alpha-1)+(1-\alpha) \log \alpha-\log \left(\frac{R T}{n F v}\right)-\frac{\alpha(1-\alpha) n F \Delta E_{\mathrm{p}}}{2.3 R T}
$$

In eq. (3), $R$ stands for gas constant $\left(8.314 \mathrm{~J} \mathrm{~K}^{-1} \mathrm{~mol}^{-1}\right), v$ for sweep rate $\left(0.1 \mathrm{~V} \mathrm{~s}^{-1}\right), \alpha$ is transfer coefficient, $T$ is temperature, $\mathrm{K} ; F$ is Faraday constant $\left(96485 \mathrm{~A} \mathrm{~s} \mathrm{~mol}^{-1}\right), n$ is the number of transferred electrons $(n=2)$ and $\Delta E_{\mathrm{p}}$ represents potential difference $(V)$ of cathodic and anodic redox peaks.

\section{Surface enzyme density}

The surface concentration of immobilized enzyme in $\mathrm{mol} \mathrm{cm}^{-2}$ was evaluated using CV measurements and Brown-Anson model [46]:

$$
i_{\mathrm{p}}=n^{2} F^{2} \Gamma \frac{A v}{4 R T}
$$

In eq. (4), $A$ represents the electrode geometrical surface area $\left(0.66 \mathrm{~cm}^{2}\right)$, and $\Gamma$ stands for the enzyme concentration on MWCNT nanocomposite of the fabricated bioanode surface. Other symbols have their already explained meaning.

\section{Results and discussion}

\section{Surface morphology analysis using scanning electron microscope}

The structure and morphology of fabricated PG bioanodes (COOH-MWCNT/PG, GOx/COOHMWCNT/PG) were studied using scanning electron microscopy (SEM). SEM images with $500 \mathrm{~nm}$ magnification taken during various stages of fabrication, are shown in Figure 2. Different grades of PG have exhibited different morphological characteristics due to the variation in their composition. 
a

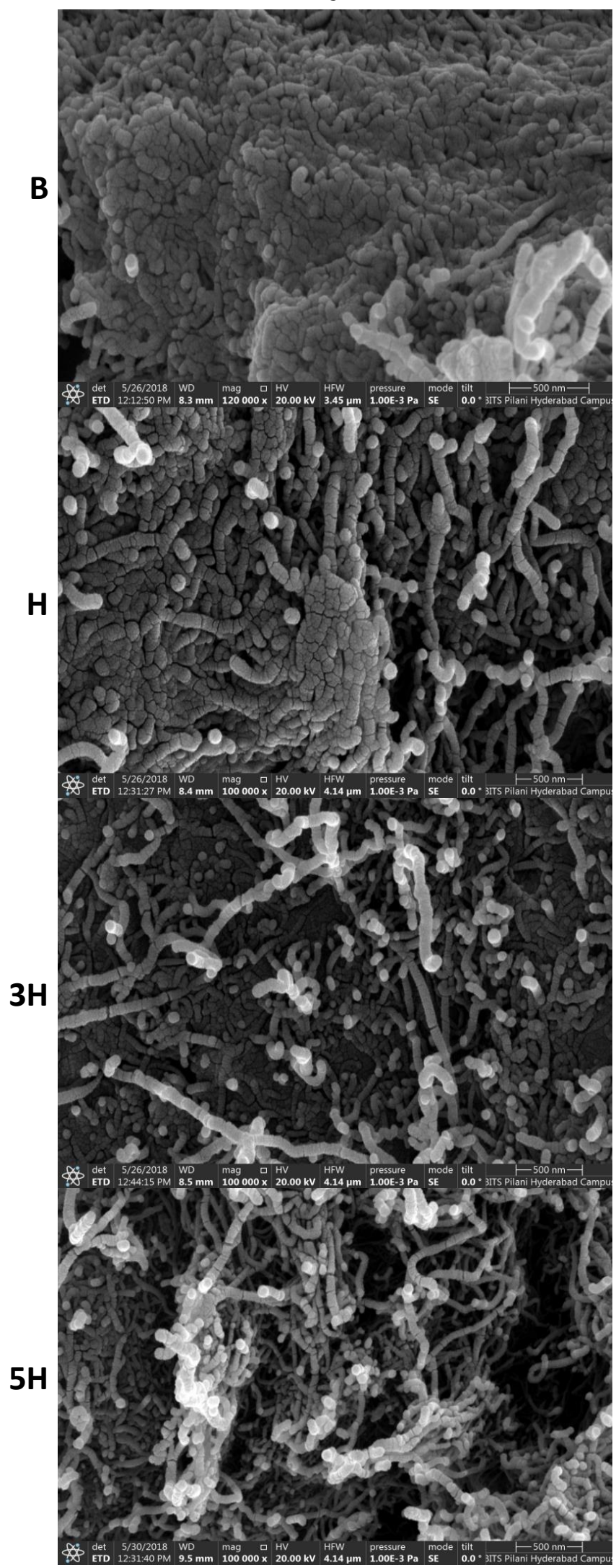

b

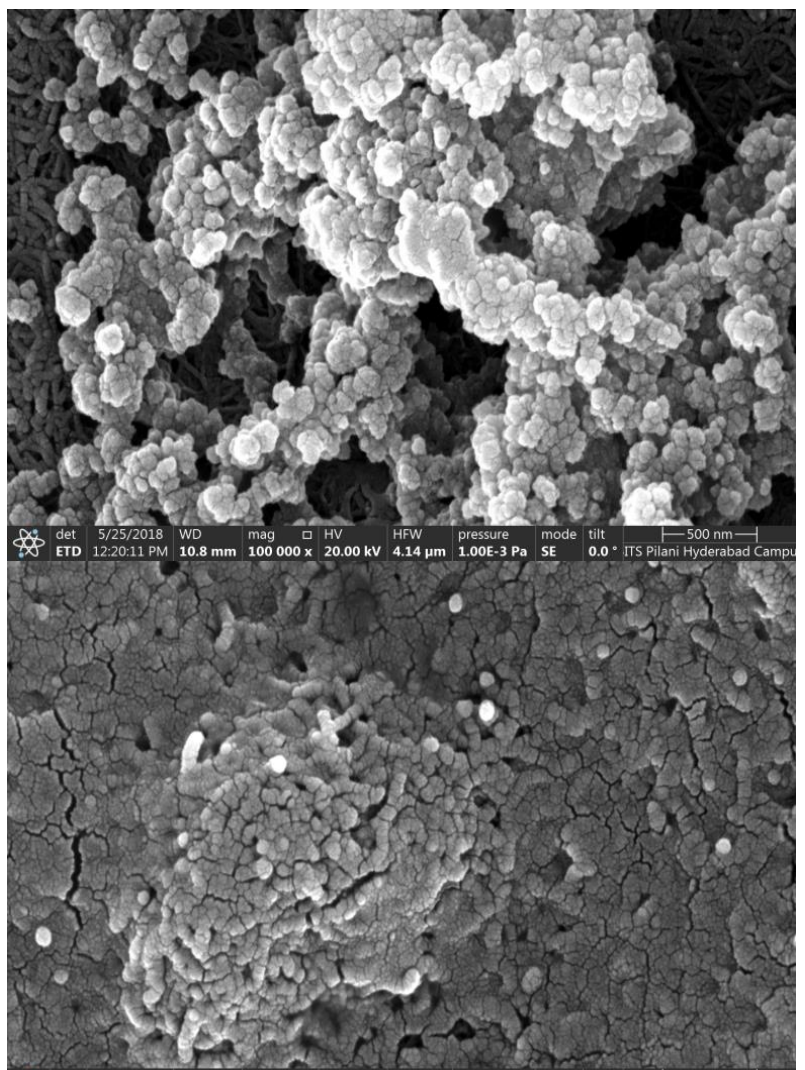

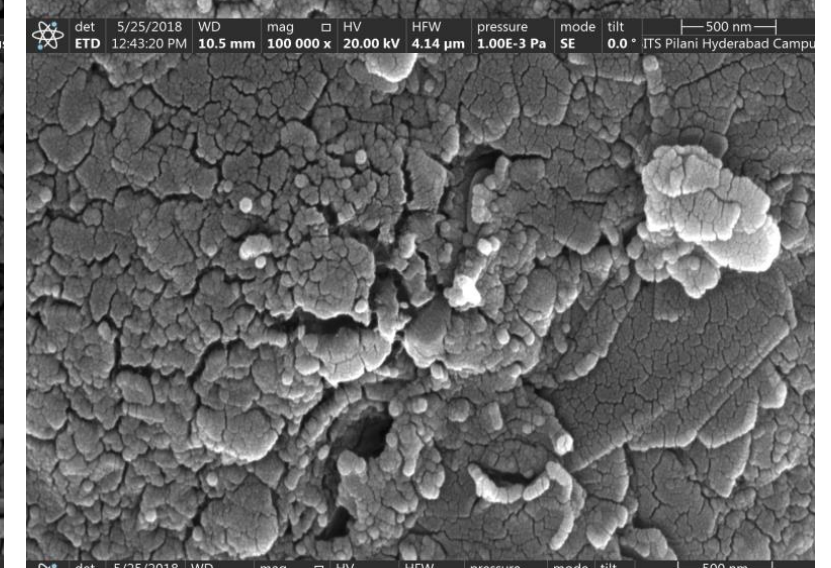

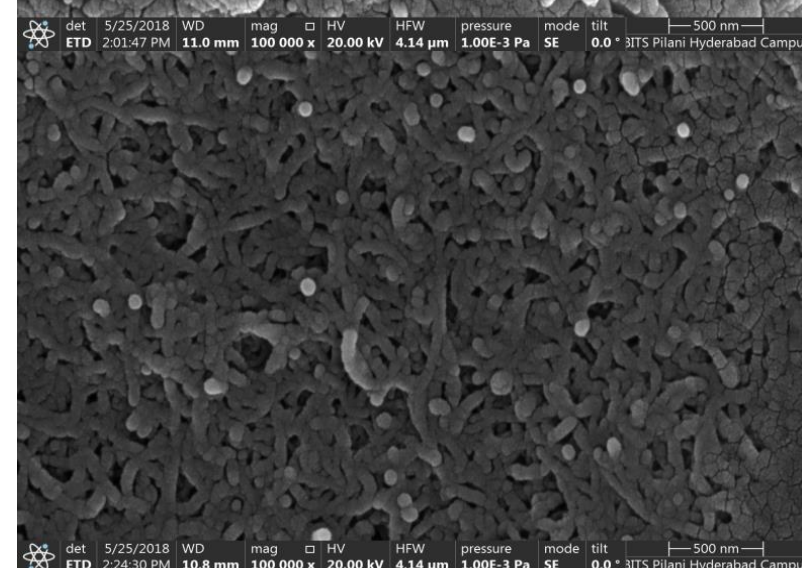

Figure 2. SEM micrographs of fabricated (a) $\mathrm{COOH}-\mathrm{MWCNT/PG}$ and (b) $\mathrm{GO} / \mathrm{COOH}$ $M W C N T / P G$ of $B, H, 3 H$, and $5 H$ grades

Figure 2a shows SEM images of $\mathrm{COOH}-M W C N T / P G$ with a network of MWCNTs distributed on the surfaces of PG of various grades. From SEM images, it can be seen that a relatively high density of MWCNT carpet is observed on B-grade PG when compared to other grades, with noticeably large 
quantities of attachment of MWCNT to PG surface. This can be attributed to the porous network structure of B-grade pencil which remains undisturbed by the small amount of binder content. In the case of other grades of pencils, however, the increasing binder content resulted in the blockage of redox sites of the surface functional groups, resulting in sparse deposition as can be seen in SEM images of other PG electrodes. It is assumed that by dip-coating of MWCNT, an increased electrode surface for anchoring of enzymes is provided with improved accessibility of redox species towards immobilized enzymes [47].

Figure $2 \mathrm{~b}$ shows SEM images of GOx/COOH-MWCNT/PG after GOx immobilization. It is evident that B-grade PG has distinct morphology with relatively high GOx coverage due to greater enzyme loading than at other grades PG. It can be inferred that B-grade PG with its dense deposition of MWCNT matrix with nano-wired structure provides a relatively large surface area that shows affinity towards GOx enzyme, resulting in greater immobilization of GOx on the electrode surface.

\section{Surface morphology analysis using energy dispersive X-ray spectroscopy}

In addition to SEM, energy dispersive X-ray spectroscopy (EDX) analysis was employed to confirm the presence of immobilized GOx enzyme on modified PG electrode surface. Figure 3 displays carbon (C) and oxygen (O) contents before and after GOx casting on MWCNT matrix of different grades PG. Before the immobilization of GOx, the unmodified PG showed low oxygen and higher carbon content. After GOx immobilization, however, the oxygen content is increased, and the carbon content reduced. This observation confirms the association of GOx enzyme layer on the surface of modified PG electrode. Relative to other tested grades, higher difference of oxygen and carbon contents before and after GOx immobilization was recorded for B-grade PG, indicating the highest enzyme immobilization among all tested grades of pencils.

It is also evident that the oxygen to carbon ratio for all tested grades of PG is ranging from 13 to $30 \%$ (O/C ratio for B grade PG $13 \%$ ), what is close to the $\mathrm{O} / \mathrm{C}$ ratio of polished glassy carbon electrode (8-15\%) [18].

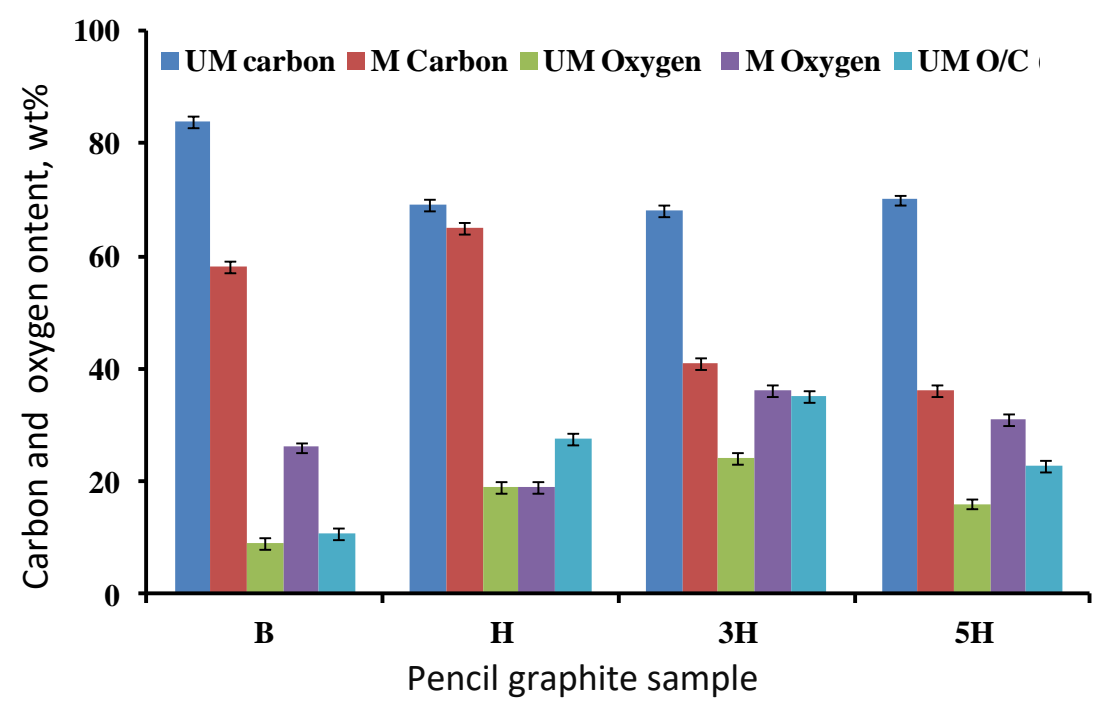

Figure 3. EDX characterization of carbon and oxygen contents of modified and unmodified PG based bioanode (UM-unmodified; M-modified).

\section{Electrode characterization using electron transfer kinetics}

The electrochemical reduction/oxidation of $\left[\mathrm{Fe}(\mathrm{CN})_{6}\right]^{-3} /\left[\mathrm{Fe}(\mathrm{CN})_{6}\right]^{-4}$ redox couple was used to compute the kinetics of electron transfer at modified PG electrodes (COOH-MWCNT/PG). The CV 
curves for $\mathrm{COOH}-\mathrm{MWCNT} / \mathrm{PG}$ tested in $4.0 \mathrm{mM}\left[\mathrm{Fe}(\mathrm{CN})_{6}\right]^{-3}$ dissolved in $100 \mathrm{mM} \mathrm{KNO}_{3}$ within the voltage range of -0.2 to $0.8 \mathrm{~V}$ at $10 \mathrm{mV} \mathrm{s}^{-1}$, are shown in Figure 4.

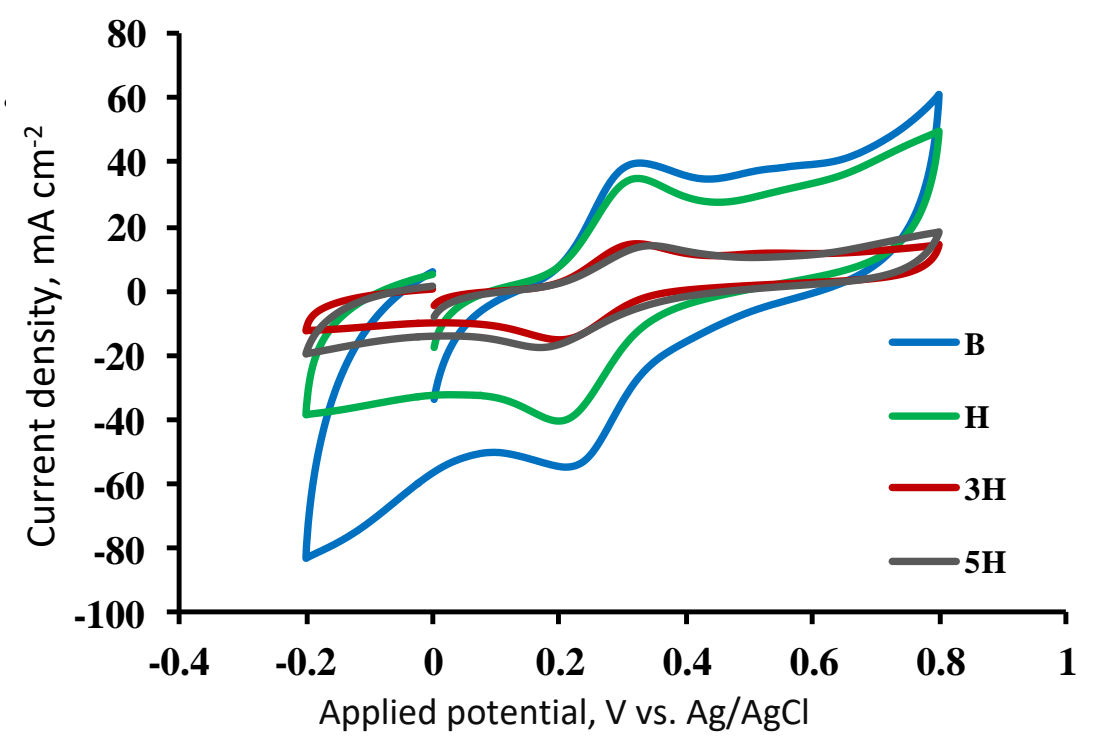

Figure 4. Cyclic voltammograms for $\mathrm{COOH}-\mathrm{MWCNT/PG}$ electrode of various grades in $0.1 \mathrm{M} \mathrm{KNO}_{3}$ containing $4.0 \mathrm{mM} \mathrm{K}_{3} \mathrm{Fe}(\mathrm{CN})_{6}$ at $10 \mathrm{mV} \mathrm{s}^{-1}$ scan rate.

The highest peak currents are observed for B-grade pencil and the ratio of cathodic $\left(i_{\mathrm{pc}}\right)$ and anodic ( $\left.i_{\mathrm{pa}}\right)$ peak currents is close to 1.0, indicating reversible electron transfer kinetics [48]. Also, this grade of $P G$ bioanode showed less anodic and cathodic peak potential difference $\left(\Delta E_{p}\right)$ (which is a basis for electrochemical reversibility [46]), indicating that the heterogeneous pseudo reversible electron transfer process is present [40]. The respective peak current densities and $\Delta E_{\mathrm{p}}$ values of all tested PG grades are summarized in Table 2.

\section{Effective electrode surface area comparison}

Electrochemical reaction of $\left[\mathrm{Fe}(\mathrm{CN})_{6}\right]^{-4} /\left[\mathrm{Fe}(\mathrm{CN})_{6}\right]^{-3}$ redox couple was also used for evaluation of effective electrode surface area (ESA) of modified PG electrodes (COOH-MWCNT/PG) of various grades. Resulting CV curves of tested $\mathrm{COOH}-\mathrm{MWCNT/PG}$ electrodes showed well defined redox peaks for the scan rate range $10-100 \mathrm{mVs}^{-1}$ and the linear expression was observed for peak currents plotted vs. square root of scan rates. Using Randles-Ševčik equation defined by eq. (1), the values of ESA were calculated using eq. (2) for all grades of $\mathrm{COOH}-\mathrm{MWCNT/PG}$ and listed in Table 2. The highest ESA was obtained for B-grade $\mathrm{COOH}-\mathrm{MWCNT/PG}$, indicating high deposition of MWCNT as can also be observed from SEM images.

Table 2. Summary of electrochemical parameters for $\left[\mathrm{Fe}(\mathrm{CN})_{6}\right]^{-4} /\left[\mathrm{Fe}(\mathrm{CN})_{6}\right]^{-3}$ redox reaction at $\mathrm{COOH}$ $M W C N T / P G$ of various grades

\begin{tabular}{ccccccc}
\hline Pencil grade & $i_{\mathrm{pa}} / \mu \mathrm{A} \mathrm{cm} \mathrm{cm}^{-2}$ & $i_{\mathrm{pc}} / i_{\mathrm{pa}}$ & $\Delta E_{\mathrm{p}} / \mathrm{mV}$ & Average value of ESA, $\mathrm{cm}^{2}$ & $\mathrm{SD}(\mathrm{n}=3)$ & Standard error, \% $(\mathrm{n}=3)$ \\
\hline $\mathrm{B}$ & 1013 & 1.06 & 71 & 0.34 & 0.01 & 1 \\
\hline $\mathrm{H}$ & 968 & 1.37 & 100 & 0.28 & 0.03 & 1 \\
\hline $3 \mathrm{H}$ & 896 & 1.25 & 103 & 0.30 & 0.03 & 1 \\
\hline $5 \mathrm{H}$ & 900 & 1.04 & 152 & 0.33 & 0.03 & $1 \%$ \\
\hline
\end{tabular}

Electrochemical characterization using electrochemical impedance spectroscopy

Electrochemical impedance spectroscopy (EIS) was opted to characterize the interface properties of fabricated PG based bioanodes during their interaction with PBS electrolyte containing $5 \mathrm{mM}$ 
glucose. In general, EIS curves reveal semicircles and straight lines at high and low frequencies, respectively. The diameter of the semicircle corresponds to the charge transfer resistance $\left(R_{\mathrm{ct}}\right)$ of the redox reaction, whilst the straight line represents the superiority of mass diffusion control effect over the charge transfer process [42].

Figure 5 shows electrochemical impedance spectra (Nyquist plots) of GOx/COOH-MWCNT/PG recorded at $0 \mathrm{~V} v$ s. $\mathrm{Ag} / \mathrm{AgCl}$ in $\mathrm{PBS}(0.1 \mathrm{M}, \mathrm{pH} 7.0)$ containing $5 \mathrm{mM}$ glucose and $2 \mathrm{mM} \mathrm{PBQ}$ as a mediator. It can be observed from impedance spectra in Figure 5 that GOx/COOH-MWCNT/PG electrodes have undergone diffusion controlled redox reaction indicated by straight lines at low frequencies. At high frequencies, however, well defined semicircles corresponding to interfacial charge transfer resistance coupled to double-layer capacitance are noticed for $\mathrm{GOx} / \mathrm{COOH}$ MWCNT/PG of all tested grades. The evaluated $R_{\text {ct }}$ values are summarized in Table 3 , showing variations between 2 to $8 \Omega \mathrm{cm}^{2}$. It can also be inferred that B-grade GOx/COOH-MWCNT/PG offered the lowest resistance to electron transfer among all tested $P G$ bioanodes. This may be attributed to the deposition of dense conducting matrix of MWCNT on PG surface. Larger value of $R_{\mathrm{ct}}$ for $3 \mathrm{H}$-grade PG may be due to large amount of clay content, as also seen by EDX analysis, which offers more resistance for electron transfer.

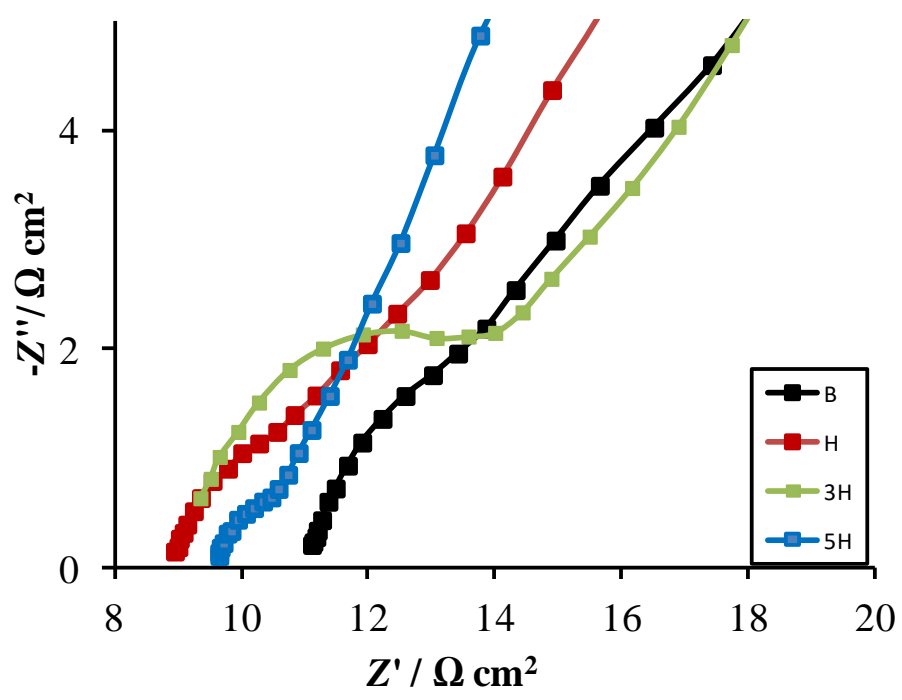

Figure 5. Nyquist plots of GOx/COOH-MWCNT/PG bioanodes fabricated from various grades of $P G$ in $0.1 \mathrm{M}$ pH 7.0 PBS containing $5 \mathrm{mM}$ glucose and $2 \mathrm{mM} \mathrm{PBQ}$. Frequency range: $10 \mathrm{kHz}-10 \mathrm{mHz}$; Amplitude: $5 \mathrm{mV}$

\section{Electrochemical characterization of $\mathrm{GOx} / \mathrm{COOH}-\mathrm{MWCNT/PG}$ electrodes using $\mathrm{CV}$}

Biocatalytic activity

The biocatalytic activity of GOx/COOH-MWCNT/PG based bioanodes towards glucose oxidation was also tested using CV. All the experiments were carried out in $\mathrm{N}_{2}$ gas saturated $0.1 \mathrm{M}, \mathrm{pH}$ 7.0 PBS containing $5 \mathrm{mM}$ glucose at the sweep rate of $10 \mathrm{mVs}^{-1}$. The resulting CV curves are presented in Figure 6, showing well defined oxidation peaks at potentials between 200 to $300 \mathrm{mV}$ for all grades of PG bioanodes. Varying current densities are observed with the highest peak current density of $4.25 \mathrm{~mA} \mathrm{~cm}^{-2}$ recorded at peak potential of $253 \mathrm{mV}$ for B-grade bioanode. This may be due to the enhanced surface area attained by increasing amount of MWCNT deposition as can be seen from SEM images and high graphite content [18]. 


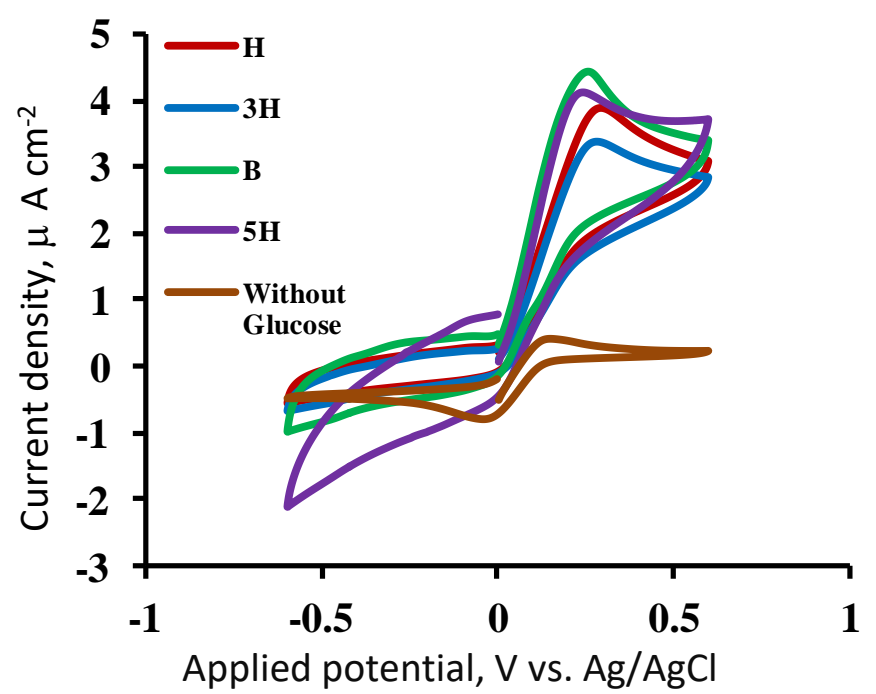

Figure 6. $\mathrm{CVs}$ of GOx/COOH-MWCNT/PG bioanodes of different grades in $0.1 \mathrm{M} \mathrm{PBS} p \mathrm{H}$ 7.0, containing $5 \mathrm{mM}$ glucose, recorded at $10 \mathrm{mVs}^{-1}$.

Immobilized GOx enzyme kinetics

Using the same CV studies, anodic peak currents were plotted against a series of scan rates for each fabricated PG bioanode. A linear raise in anodic peak current with increase in sweep rate was observed. Using Laviron (eq. (3)) and Brown-Anson equation (eq. (4)), the electron transfer rate (ETR) constant $(\gamma)$ and surface concentration $(I)$ of deposited nanobiocomposite for all tested PGs were determined and listed in Table 3. The values of ETR constants for all tested grades of pencil leads are varied from 2.0 to $5.4 \mathrm{~s}^{-1}$, and the highest surface concentration of enzymes biocomposite is observed for B-grade bioanode showing the fastest ETR $\left(5.39 \mathrm{~s}^{-1}\right)$, what agrees with SEM results.

Table 3. Electrochemical characteristics of GOx/COOH-MWCNT/PG bioanodes

\begin{tabular}{ccccc}
\hline Pencil grade & $R_{\mathrm{ct}} / \Omega \mathrm{cm}^{2}$ & $i_{\mathrm{pa}} / \mu \mathrm{Acm}^{-2}$ & $\gamma / \mathrm{s}^{-1}$ & $\Gamma / \mathrm{mol} \mathrm{cm}^{-2} \times 10^{-10}$ \\
\hline $\mathrm{B}$ & 2 & 4250 & 5.39 & 2.42 \\
\hline $\mathrm{H}$ & 5 & 163 & 1.96 & 1.79 \\
\hline $3 \mathrm{H}$ & 8 & 3086 & 2.62 & 1.82 \\
\hline $5 \mathrm{H}$ & 3 & 3910 & 3.87 & 2.27 \\
\hline
\end{tabular}

Biofuel cell performance of GOx/COOH-MWCNT modified PG bioanode

To validate the application of fabricated bioanodes for EGBFC, a prototype membrane-less enzymatic glucose biofuel cell was assembled using GOx/COOH-MWCNT/PG as bioanode and platinum wire as cathode. Both electrodes were immersed in PBS (0.1 M, pH 7.0) contained in $10 \mathrm{ml}$ beaker at atmospheric conditions. Figure 7a shows the real image of assembled membrane-less enzymatic glucose biofuel cell. It can be clearly observed from Figure 7a, that PG-based bioanode of B-grade in PBS $(0.1 \mathrm{M}, \mathrm{pH}$ 7.0) containing $5 \mathrm{mM}$ glucose is well-suited for further miniaturization. Figure $7 \mathrm{~b}$ presents current density $(I)$ and power density $(P)$ of EGBFC ( $/ v s$. $P$ and $/ v$ s. $V$ curves) as a function of operation cell voltage taken at room temperature $\left(25 \pm 3^{\circ} \mathrm{C}\right)$. The current density was calculated with respect to the electrochemical active surface area (ESA) of bioanode. Figure $7 \mathrm{~b}$ shows that open circuit potential (OCP) and maximum current density of EGBFC are $149 \pm 3 \mathrm{mV}$ and $38 \pm 0.7 \mu \mathrm{A} \mathrm{cm}^{-2}$, respectively. Further, a maximum power density of $0.789 \mu \mathrm{W} \mathrm{cm}^{-2}$ can be attained at $141 \mathrm{mV}$. This value is very close to that of anodes made from carbon cloth $[49,50]$ and even greater than those of anodes based on reduced graphene oxide (rGO/MWCNT) based carbon [51]. This proves the applicability of the fabricated bioanode to EGBFC. At the same time, the value of 
maximum power density is somewhat smaller than for carbon or MWCNT based wired enzyme bioanodes [52-54]. However, the unique advantages of PG like low cost, quick surface renewal and ease of modification and miniaturization, off-set its lower performance levels, maintaining thus applicability of PG to miniaturized bioelectronic systems.

a

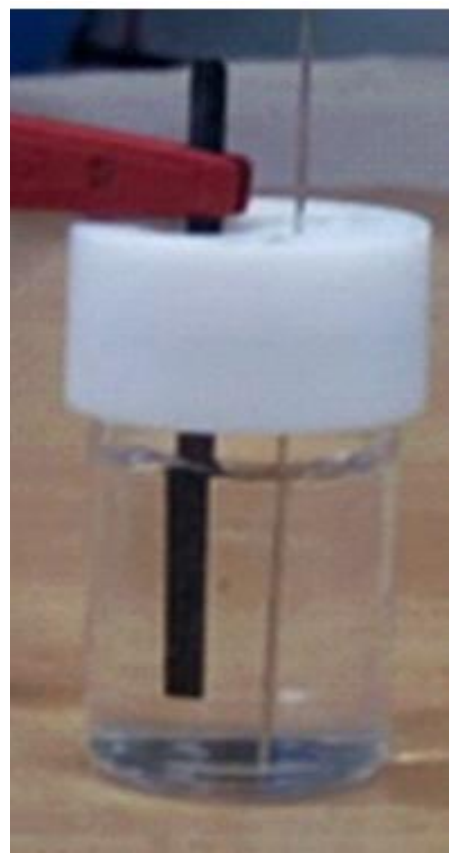

b

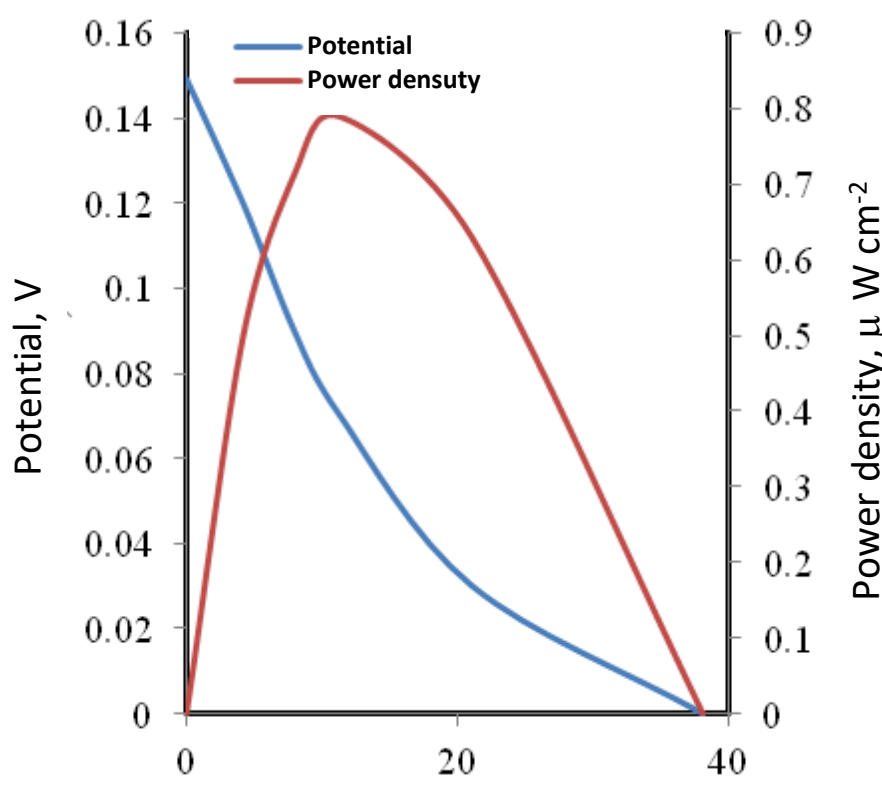

Current density, $\mu \mathrm{A} \mathrm{cm}{ }^{-2}$

Figure 7. a) Real image of the assembled single chamber membrane-less EGBFC with an optimized grade PG as bioanode and platinum wire as biocathode in contact with $5 \mathrm{mM}$ glucose dissolved in $0.1 \mathrm{M}, \mathrm{pH} 7.0 \mathrm{PBS}$ containing $3 \mathrm{mM}$ ABTS and $3 \mathrm{mM} P B Q$ as anodic and cathodic mediators and under air saturated conditions. b) Potential and power density vs. current density plots of EGBFC containing optimized PG bioanode obtained by polarization studies at $25 \pm 3{ }^{\circ} \mathrm{C}$.

\section{Conclusions}

This work demonstrates the application of modified pencil graphite (PG) of different grades as suitable bioanodes for enzymatic glucose biofuel cell (EGBFC). Morphological characterization of tested $P G$ of grades $\mathrm{H}, 3 \mathrm{H}, 5 \mathrm{H}$, and $\mathrm{B}$ have indicated some variations in enzyme immobilization on the surface of PG, based on their composition and surface structure. The tested PG bioanodes exhibited positive responses towards glucose oxidation reaction with the fastest electron transfer rate recorded for B-grade PG. The half-cell assembly with this PG grade bioanode showed the highest current density of $4.25 \mathrm{~mA} \mathrm{~cm}^{-2}$ under physiological glucose concentration conditions. The obtained results reveal that physical and electrochemical characteristics of B-grade PG bioanode are comparable to those of conventional carbon and glassy carbon electrode substrates.

The membrane-less enzymatic glucose biofuel cell assembled with B-grade PG bioanode showed OCP at $149 \mathrm{mV}$, maximum power density of $0.789 \mu \mathrm{W} \mathrm{cm}{ }^{-2}$ and current density of $38 \pm 0.7 \mu \mathrm{Acm}^{-2}$ at $141 \mathrm{mV}$ voltage, respectively. Since these values are very close to those of anodes made from carbon cloth modified with MWCNT and even greater than those of anodes based on rGO/MWCNT based carbon, the applicability of the fabricated bioanode to EGBFC becomes clear.

The performance can be further optimized by subjecting PG to additional surface modifications with nanomaterials and conductive polymers. Alternate enzyme immobilizing techniques can also be explored to enhance enzyme reaction kinetics. The performance is also likely to vary by introduction of PG based biocathode to realize fully assembled EGBFC using PG electrodes. Once 
optimized, a lab scale membrane-less EGBFC would be assembled with the optimized PG as bioanode and biocathode with laccase and glucose oxidase enzymes. Evaluating the performance of EGBFC assembled with the optimized grade PG electrodes will give further insights into possible practical real time applications.

\section{References}

[1] D. Kashyap, P. S. Venkateswaran, P. K. Dwivedi, YH. Kim, GM. Kim, A. Sharma, S. Goel, International Journal of Nanoparticles 8 (2015) 61-81.

[2] J. Kim, H. Jia, P. Wang, Biotechnology Advances 24 (2006) 296-308.

[3] M. Holzinger, A. Le Goff, S. Cosnier, Electrochimica Acta 82 (2012) 179-190

[4] J. M. Friedrich, C. Ponce-de-León, G. W. Reade, F. C. Walsh, Journal of Electroanalytical Chemistry 561 (2004) 203-217.

[5] A. K. Sarma, P. Vatsyayan. P. Goswami, S. D. Minteer, Biosensors and Bioelectronics 24 (2006) 23132322.

[6] K. Aoki, T. Okamoto, H. Kaneko, K. Nozaki, A. Negishi, Journal of Electroanalytical Chemistry and Interfacial Electrochemistry 263 (1989) 323-331.

[7] I. G. David, D. E. Popa, M. Buleandra, Journal of Analytical Methods in Chemistry (2017) Article ID 1905968 https://doi.org/10.1155/2017/1905968

[8] J. K. Kariuki, Journal of the Electrochemical Society 159 (2012) 747-751.

[9] P. H. C. P. Tavare, P. J. S. Barbeira, Journal of Applied Electrochemistry 38 (2008) 827-832.

[10] E. Alipour, M. R. Majidi, A. Saadatirad, S. M. Golabi, A. M. Alizadeh, Electrochimica Acta 91 (2103) 3642.

[11] Z. Q. Gong, A. N. Sujari, S. Ab Ghani, Electrochimica Acta 65 (2012) 257-265.

[12] L. Liv, N. Nakiboglu, Turkish Journal of Chemistry 40 (2016) 412-421.

[13] J. Wang, A. N. Kawde, E. Sahlin, Analyst 125 (2000) 5-7.

[14] J. Wang, A. N. Kawde, Analytica Chimica Acta 413 (2001) 219-224.

[15] E. Alipour, S. Gasemlou, Analytical Methods 4 (2012) 2962-2969.

[16] A. Ozcan, Y. Sahin, Biosensors and Bioelectronics 25 (2010) 2497-2502.

[17] P. Kara, B. Meric, A. Zeytinoglu, M. Ozsoz, Analytica Chimica Acta 518 (2004) 69-76.

[18] A. M. Bond, P. J. Mahon, J. Schiewe, V. Vicente-Beckett, Analytica Chimica Acta 345 (1997) 67-74.

[19] M. D. Rubianes, G. A. Rivas, Analytical Letters 36 (2003) 329-345.

[20] S. Buratti, M. Scampicchio, G. Giovanelli, S. Mannino, Talanta 75 (2008) 312-316.

[21] A. N. Kawde, N. Baig, M. Sajid, RSC Advances 6 (2016) 91325-40.

[22] M. R. Akanda, M. Sohail, M. A. Aziz, A. N. Kawde, Electroanalysis 28 (2016) 408-424.

[23] R. Ansari, A. F. Delavar, A. Aliakbar, A. Mohammad-Khah, Journal of Solid State Electrochemistry 16 (2012) 869-875.

[24] J. L. Ling, A. Khan, B. Saad, S. Ab Ghani, Talanta 88 (2012) 477-483.

[25] M. K. Ali, R. Ansari, A. F. Delavar, Z. Mosayebzadeh, Bulletin of the Korean Chemical Society 33 (2012) 1247-1252.

[26] A. N. Kawde, M. Aziz, N. Baig, Y. Temerk, Journal of Electroanalytical Chemistry 740 (2015) 68-74.

[27] M. A. Aziz, A. N. Kawde, Talanta 115 (2013) 214-221.

[28] H.C. Kalachar, Y.A. Naik, International Journal of Chem Tech Research 3 (2011) 1237-1245.

[29] C. Cheng, K.C. Chang, C.S. Chena, D.G. Pijanowska, Journal of Chinese Chemical Society 58 (2011) 739748.

[30] G. Congur, M. Plucnara, A. Erdem, M. Fojta, Electroanalysis 27 (2015) 1579-1586.

[31] A.A. Ensafi, E. Khoddami, B. Rezaei, Talanta 116 (2013) 1113-1120.

[32] J. Narang, N. Malhotra, G. Singh, C.S. Pundir, Biosensors and Bioelectronics 66 (2015) 332-337.

[33] M. R. Majidi, K. Asadpour-Zeynali, B. Hafezi, Microchimica Acta 169 (2010) 283-288.

[34] F. Kuralay, T. Vural, C. Bayram, E.B. Denkbas, S. Abaci, Colloids and Surfaces B: Biointerfaces 87 (2011) 18-22.

[35] A. Erdem, M. Muti, H. Karadeniz, G. Congur, E. Canavar, Colloids and Surfaces B: Biointerfaces 95 (2012) 222-228.

[36] E. Alipour, M.R. Majidi, O. Hoseindokht, Journal of Chinese Chemical Society 62 (2015) 461-468. 
[37] M. Bandapati, P.K. Dwivedi, B. Krishnamurthy, Y. H. Kim, G. M. Kim, S. Goel, International Journal of Hydrogen Energy 42 (2017) 27220-27229.

[38] M. Bandapati, B. Krishnamurthy, S. Goel, IEEE Transactions on Nanobioscience 18 (2) (2019) 170-175.

[39] K. Ahmad, M. Naushad, International Journal of Hydrogen Energy 39 (2014) 7417-7421.

[40] D. Ivnitski, B. Branch, P. Atanassov, C. Apblett, Electrochemical Communication 8 (2016) 1204-1210.

[41] J. Shi, J. C. Claussen, E.S. McLamore, A. ul Haque, D. Jaroch, A.R. Diggs, P. Calvo-Marzal, J. L. Rickus, D.M. Porterfield, Nanotechnology 22(35) (2011) 355502.

[42] D. Kashyap, P.K. Dwivedi, J.K. Pandey, Y.H. Kim, G.M. Kim, A. Sharma, S. Goel, International Journal of Hydrogen Energy 39 (2014) 20159-170.

[43] T. Ikeda, I. Katasho, M. Kamei, M. Senda, Agricultural and Biological Chemistry 48 (1984) 1969-1976.

[44] A. J. Bard, L.R. Faulkner, Electrochemical Methods: Fundamentals and Applications, Wiley, 2000.

[45] E. Laviron, Journal of Electroanalytical Chemistry and Interfacial Electrochemistry 10 (1979) 19-28.

[46] A. P. Brown, F. C. Anson, Analytical Chemistry 11 (1977)1589-1595.

[47] F. Lopez, S. Zerria, A. Ruff, W. Schuhmann, Electroanalysis 7 (1977) 1311-1318.

[48] K. Gong, M. Zhang, Y. Yan, L. Su, L. Mao, S. Xiong, Y. Chen, Analytical Chemistry 76 (2005) 6500-5.

[49] B. C. Kim, I. Lee, S. J. Kwon, Y. Wee, K.Y. Kwon, C. Jeon, H. J. An, H. T. Jung, S. Ha, J. S. Dordick, J. Kim, Scientific Reports 7 (2017) 40202.

[50] M. Ammam, J. Fransaer, Biotechnology and Bioengineering 109 (2012) 1601-1609.

[51] S. Palanisamy, S. Cheemalapati, S. M. Chen, International Journal of Electrochemical Science 11 (2012) 11477-87.

[52] Y. Li, S. M. Chen, R. Saraswathi, International Journal of Electrochemical Science 6 (2011) 3776-3788.

[53] R. Haddad, W. Xia, D. A. Guschin, S. Pöller, M. Shao, J. Vivekananthan, M. Muhler, W. Schuhmann, Electroanalysis 25 (2013) 59-67.

[54] A. Kumar, S. Sharma, L. M. Pandey, P. Chandra, Materials Science for Energy Technologies 1 (2018) 3848.

(C2020 by the authors; licensee IAPC, Zagreb, Croatia. This article is an open-access article distributed under the terms and conditions of the Creative Commons Attribution license (http://creativecommons. org/licenses/by/4.0/) 